\title{
A Mindfulness Curriculum: High School Students' Experiences of Yoga in a Nova Scotia School
}

\author{
Karen A. Berezowski, Christopher M. Gilham, and Daniel B. Robinson
}

\begin{abstract}
This article reports on results from a narrative inquiry into the experiences of four students who completed an elective yoga course as part of their high school program in the province of Nova Scotia, Canada. Semi-structured interviews were conducted to understand the participants' stories of their yoga experiences. Overall, students were able to express and give examples of how yoga made them feel stronger, happier, kinder, and more self-confident. We suggest that Yoga 11 is a mindfulness curriculum, inherently. This research might be of particular interest to others similarly engaged in research related to mental health and mindfulness in education.
\end{abstract}

\section{Background}

Yoga has been defined as a comprehensive mind-body experience that involves physical postures and movement, breathing exercises, relaxation, and meditation. These practices are meant to develop selfobservation without judgment (Conboy, Noggle, Frey, Kudesia, \& Khalsa, 2013). Moreover, this practice necessitates focused movement and breathing - with the ultimate goal of unifying the self at physical, emotional, cognitive, spiritual, and social levels (Conboy et al., 2013). Yoga is often described as a contemplative or mindfulness practice (Salmon, Lush, Jabonski, \& Sephton, 2009; Shelov, Suchday, \& Friedberg, 2009).

Among yoga's many descriptions, practices, and benefits, mindfulness is a common core concept. Mindfulness, the "intentional cultivation of moment-by-moment non-judgmental focused attention and awareness" (Meiklejohn et al., 2012, p. 291) is a purposeful part of yoga, particularly when it is viewed as a contemplative practice (Greenberg \& Harris, 2012). Though additional mindfulness practices exist and have been introduced into school communities (e.g., meditation, attention training), only yoga exists in Canada as an actual curricular course. Consequently, it has great potential to reach many students over sustained periods of time.

Increasingly, educators in $\mathrm{K}-12$ schools have been introducing mindfulness practices into their classrooms (Meiklejohn et al., 2012; Robinson \& Berezowski, 2016; Schonert-Reichl \& Stewart Lawlor, 2010). Recent research on mindfulness in K-12 settings has demonstrated positive results for students (Meiklejohn et al., 2012; Schonert-Reichl \& Stewart Lawlor, 2010). More specifically, research literature has revealed that there are mental and physical benefits for those (including youth) who practise yoga (Hainsworth et al., 2014; Sharma \& Haider, 2013). At the same time, Canadian educators have felt illequipped to address mental health issues with their students (Physical and Health Education Canada, 
2014a, 2014b). We suggest the ever-increasing popularity of mindfulness practices in schools could be interpreted as a response of educators to their felt need to do more for student mental health.

This paper presents the results of a recent qualitative research study on high school students' experiences with Yoga 11, an especially unique alternative physical education course offered within the province of Nova Scotia, Canada. To our best understanding, Yoga 11 is the only government-approved physical education-equivalent course in $\mathrm{K}-12$ school systems in Canada in which the curriculum itself is mindfulness. Given the research data on mindfulness in education, students within Yoga 11 might reasonably expect to experience mental health benefits. The need to uncover and understand the potential perceived benefits provided a central impetus for this inquiry. This research might be considered by educators who similarly engage in inquiry related to the mental health benefits of contemplative or mindfulness practices in educational settings.

\section{The Yoga 11 Curriculum}

The intention of the Yoga 11 curriculum is for students to develop a lifelong personal practice of yoga, to maintain physical health and wellness, and to develop healthy relationships with self and others (Nova Scotia Department of Education, 2010). The Yoga 11 curriculum is based on three modules of study. The first module, "Proper Breathing and Asana Practice," includes seven learning outcomes and is concerned, primarily, with the demonstration of various physical postures of yoga (asanas). The second module, "The Origin and Philosophy of Yoga," includes three learning outcomes based on the history of the practice. Although the ancient tradition of yoga has various forms and styles, Yoga 11 students are expected to demonstrate an understanding of Ashtanga yoga. Ashtanga yoga is described by lyengar (2002) as an eightfold path (see Figure 1) that includes guidelines for how we treat others (yamas), how we treat ourselves (niyamas), postures (asana), breathwork (pranayama), withdrawal of the senses (pratyahara), concentration (dharana), meditation (dhyana), and enlightenment (samadhi). The third module, "Integrating a Mindful Practice," also has three learning outcomes. Topics related to this module include mindful eating practices, strategies to manage emotions and stress, and the application of yoga principles outside of yoga practice. 


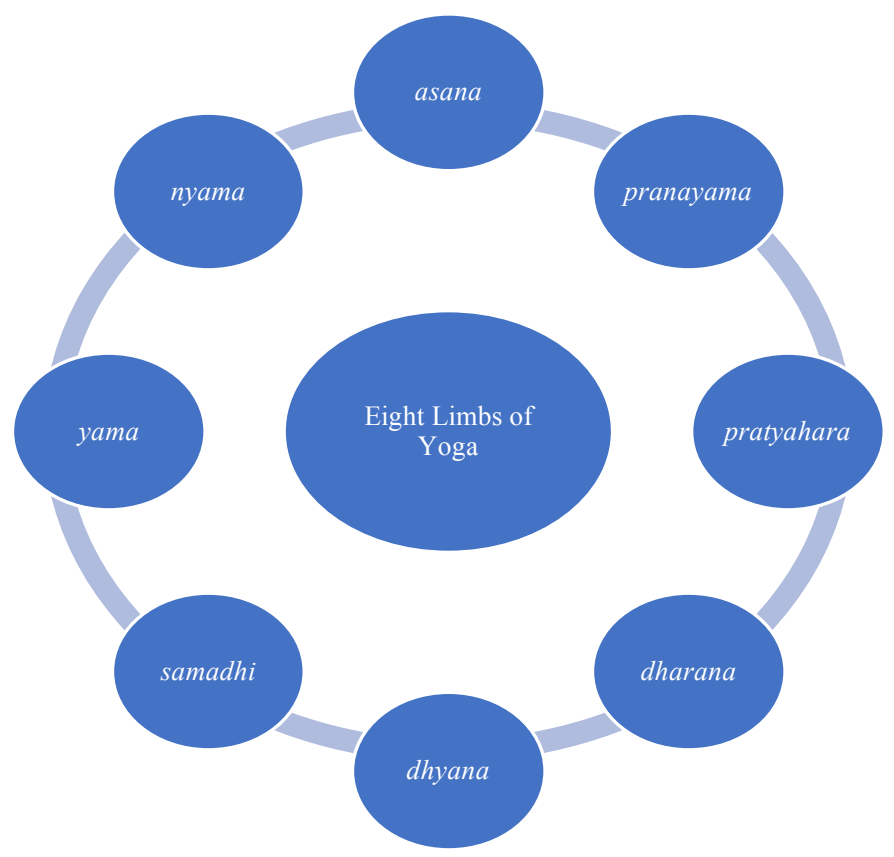

Fig. 1: Yoga's eightfold path

\section{Mental Health Benefits of Yoga for Youth}

Chugh-Gupta, Baldassarre, and Vrkljan (2013) explained that youth anxiety is an emotional state of mind that is characterized by excessive and uncontrollable worry about typical challenges such as writing tests, public speaking, or illness. This "state" anxiety is linked to these particular obstacles and life situations (Chugh-Gupta et al., 2013). Emerging evidence has suggested yoga is beneficial as a complementary intervention to talk therapy and pharmacological intervention to this state anxiety (Chugh-Gupta et al., 2013).

Sharma and Hader (2013) pointed out that a traditional yoga practice encourages slow deep breathing techniques that are used to relax the mind and body. Symptoms associated with anxiety often include short choppy breaths and yoga has been used as a therapy to treat these warning signs of anxiety. Yoga has been used by patients looking for ways to lower their heart rates and blood pressure, without depending on drug or counselling therapy. Sharma and Hader explained that yoga could be an effective alternative for patients suffering from anxiety, as the controlled breathing techniques naturally activate the parasympathetic nervous system and a relaxation response in the body.

White (2012) investigated reducing stress in school-age girls through mindful yoga. Youth report many stressors in their lives, including homework, peer pressure, being teased, receiving poor grades, bullying, standardized testing, and perceived parental pressure. Furthermore, youth can recognize feelings associated with stress (White, 2012). White suggested that, through mindful yoga, school-age youth have the ability to cognitively appraise a stressful situation and, then, generate and evaluate an effective coping strategy. 
Noggle, Steiner, Minami, and Khalsa (2012) introduced-and researched the effects of-a regular yoga program to Grade 11 and 12 physical education students from a rural high school. The students who participated in yoga indicated they had less tension and anxiety compared to the control group who had "regular" physical education. The results of this trial were used as evidence to support a larger qualitative study in the same school the following year. The researchers predicted that yoga included in the school curriculum would "improve overall student well-being by both decreasing negative and increasing positive aspects of mental health" (p. 7).

Conboy et al's (2013) follow-up study provided an assessment of yoga applied to a high school setting. They grouped the benefits of yoga into a number of categories: individual benefits, social benefits, athletic performance, bodily awareness, mental health, sleep, emotional regulation, stress reduction, interest in substance use, and academic performance. Notably, Conboy et al. found that mental health benefits included improved dedication and work ethic, greater respect for one's body, improved self-image, positive changes in food choices, increased ability to relax and breathe deeply, and stress relief.

\section{Methodology and Methods}

\section{Narrative Inquiry}

Narrative inquiry was chosen for conducting this qualitative research. Clandinin, Pushor, and Murray Orr (2007) explained that narrative inquiry as a methodological choice for research requires a particular kind of wakefulness and is distinct from other types of qualitative inquiry. Clandinin (2006) suggested that narrative inquiry is an old human practice. We tell and listen to stories about our living and it is how we create meaning in our lives. Clandinin et al. (2007) gave this analogy of narrative:

People shape their daily lives by stories of who they and others are and as they interpret their past in terms of these stories. Story, in the current idiom, is a portal through which a person enters the world and by which their experience of the world is interpreted and made personally meaningful. Viewed this way, narrative is the phenomenon studied in inquiry. Narrative inquiry, the study of experience as story, then is first and foremost a way of thinking about experience. (p. 22)

Clandinin et al. (2007) outlined three commonplaces for consideration in narrative inquiry: temporality, sociality, and place. The commonplace of temporality recognizes that research captures a moment or behaviour at a specific time; people and situations are impermanent. Narrative inquirers are also concerned with the personal and social conditions of the study participants. This is addressed by the second commonplace of sociality. A relationship of trust between the inquirer and participant is essential when engaging in narrative inquiry. The third commonplace for consideration is place. Participants' stories occur somewhere, and this place contributes to many details in participants' stories.

Attending to the structure offered by these three commonplaces gave strength to the student stories in our study. Indeed, their stories were meaningful because of the intentional recognition of the intersection of these three commonplaces. Intentionally attuning to these three commonplaces well suits a study on 
yoga as mindfulness, we offer. Noticing, or paying close attention to, what others have to say about their experiences, with a focus on the three commonplaces, is at once both a research methodology and a mindfulness exercise.

Clandinin et al. (2007) explained that narratives are portals through which a person enters and makes meaning of the world. Narrative inquiry as a research method holds interesting similarities to the ancient practice of yoga. Traditionally, yoga was taught orally, passed down through the generations from teacher to student in the form of traditional lore (lyengar, 2002). The practice was learned by doing, and could be described as active sharing. A yoga practice could also be described as narrative in nature, as it tells the story of the practitioner. The narratives of the Yoga 11 students were the concepts studied for this research, and narrative inquiry was the method used to gather information about the experiences. The stories of the Yoga 11 students revealed rich details about how the practice benefitted their health. We suggest this method and methodology are congruent with Yoga 11 as a mindfulness curriculum.

\section{Research Methods and Participants}

Data were collected through four separate semi-structured in-depth interviews (each participant took part in one interview each). These semi-structured in-depth interviews were approximately 30 to 40 minutes in length and they occurred at the school during the lunch hour or after school, as this was most convenient for the students. Interview questions followed a planned interview guide though participants were also asked a number of further probing questions to clarify points that were made or unclear. While some questions certainly presupposed students would have viewed their Yoga 11 experience favourably, others were entirely open ended. However, all responses were related to the experienced positive features of their Yoga 11 experience.

Sample interview questions included:

- Has the daily physical practice affected your body or health? If so, provide details.

- What other kinds of things have changed in your life because of your experience of Yoga?

- How do you think Yoga will continue to affect your health?

- Can you tell me a story about how yoga helped you when you were outside of your Yoga 11 class?

Interviews were audio-recorded and then subsequently transcribed verbatim.

Participants were chosen through a mixed purposeful sampling strategy (Merriam, 2009; Patton, 2001). More specifically, all invited participants were former Yoga 11 students who were less than one year removed (criterion sampling; Patton, 2001). In response to a morning video announcement at the school site, 26 former students attended an information session about the research. Twelve students returned signed consent/assent forms. From these 12 students, three female students and one male student were randomly selected (purposeful random sampling; Patton, 2001) to participate in the research interview as research participants. The 3:1 ratio for female-to-male students was purposeful in that it approximated 
the higher ratio of female to male students in the course (and in the consenting students). All four participants were former Yoga 11 students who successfully completed the course in June 2014. Cecelia, Christina, and Sally (all pseudonyms) were in grade 11 while Tommy was in grade 12 .

\section{Processing and Analyzing the Data}

Relevant ideas from the student responses were grouped into open codes. Merriam (2009) suggested that a recurring pattern would emerge that substantiates or enlivens the story of the research question, "How is Yoga 11 experienced by students?" A pattern did emerge in this study. It consisted of common student experiences in Yoga 11 that supported the related research literature, particularly with respect to the mental health benefits of yoga. The students gave concrete examples of their learning experiences and, in the process, they were able to clearly define how the yoga practice positively affected their mental health. Concomitantly, the student responses aligned with Ashtanga yoga philosophy, we offer.

\section{Positionality of Researchers/Authors}

The three of us played different roles in this research project. The first author, Karen Berezowski, was the principal investigator. Karen has considerable experience teaching Yoga 11, and is recognized as one of the pioneering influences for the inclusion of yoga within Nova Scotia schools (see Figure 2). Though not a teacher at the research site during the study, Karen taught Yoga 11 as well as other courses at the research site prior to, and subsequent to, the completion of this research. She was a graduate student at the time of the research and this study was completed as part of her Master of Education thesis. The second author, Christopher Gilham, is an expert in mental health education as well as mindfulness practices within educational and schooling contexts. As a mentor to (and now colleague of) Karen, Chris contributed to the conceptualization and writing of this paper, particularly as that conceptualization and writing relates to mindfulness. The third author, Daniel Robinson, is an expert in physical and health education curriculum, instruction, and pedagogy. He also served as Karen's thesis supervisor. In this capacity he also played a role in establishing credibility through his involvement as a second data coder. His contributions to writing are especially related to research design and analysis. 


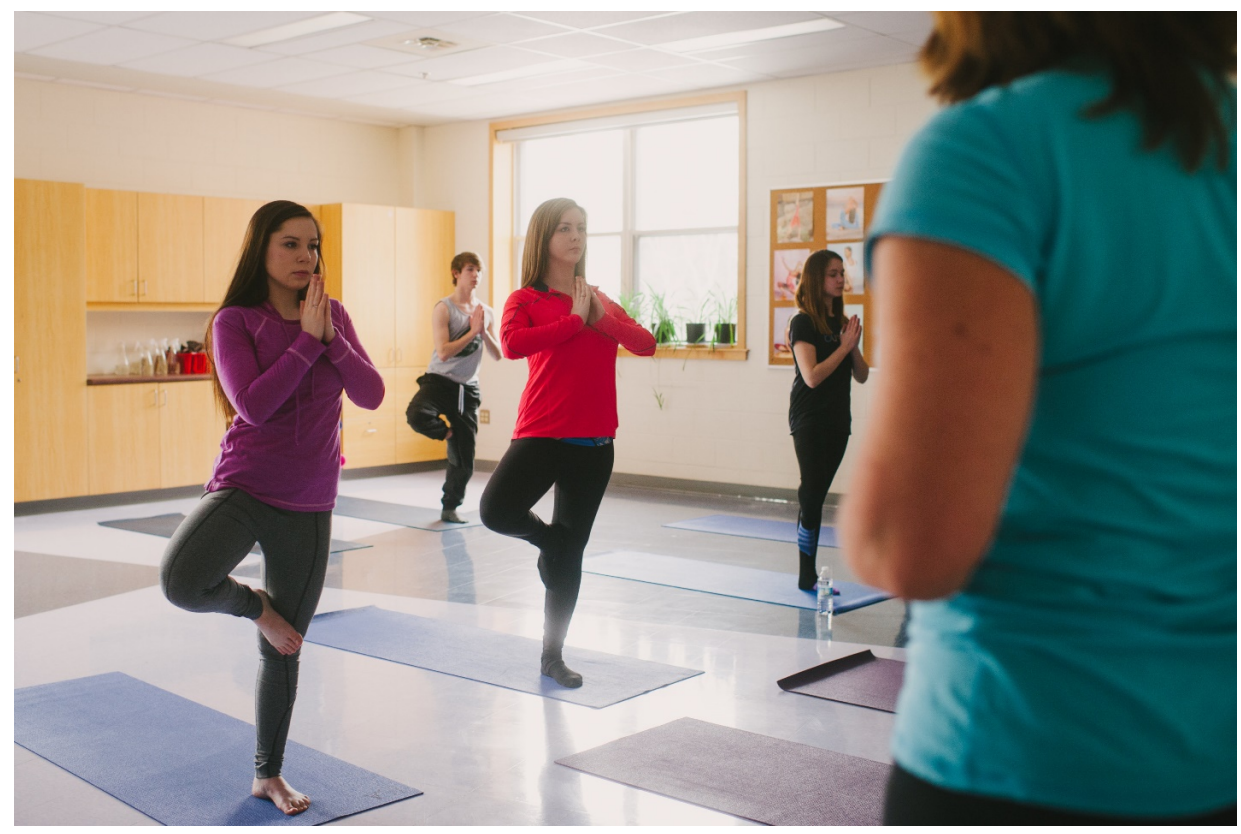

Fig. 2: Karen teaching a Yoga 11 class

Establishing our positionality might suggest a degree of bias. To this, we would encourage readers to consider our already established position on researcher bias (see Robinson \& Berezowski, 2016). That is, "we would hope that any reader with a familiarity with qualitative research might recognize that all research is impacted, in some way, by researcher bias" (p. 9). Of course, notwithstanding this position, we also believe sharing one's positionality and/or real or perceived biases is an essential task when disseminating research results, particularly when engaging in qualitative research.

\section{Compliance With Ethical Standards}

This study was completed without funding. The authors have no conflicts of interests. All procedures performed in studies involving human participants were in accordance with the ethical standards of the Government of Canada's Tri-Council Policy for the Ethical Conduct for Research Involving Humans. This research was approved by the Research Ethics Board of Saint Francis Xavier University, Antigonish, Nova Scotia, Canada. Informed consent was obtained from all individual participants included in the study.

\section{Results: Students' Experiences of the Health Benefits of Yoga 11}

Overall, students were able to express and give examples of how yoga made them feel happier, kinder, and more self-confident. For example, Sally shared that she seemed happier when she was taking Yoga 11:

I think yoga made me a happier person when I was taking it, not just because I was moving my body around, but because it was a class I actually enjoyed, and just lets people take it at their own pace... and everyone was happy and enjoying their time there. (Sally, transcript excerpt, October 2014) 
Moreover, Tommy confidently shared how his opinions changed about yoga:

It's a stereotype, you think that's not something I can do, that's a girls' class, and you really just need to break out of your shell and give it a shot because you can't really do something unless you try. (Tommy, transcript excerpt, October 2014)

Sally was also able to mindfully articulate her understanding of the importance of thinking about how her thoughts and actions can affect others:

I'm happy, not all the time, but I'm trying to stay positive and really think about others... and the way that my ways can change someone else, I never even thought about half the things that I do now, like before I took yoga. (Sally, transcript excerpt, October 2014)

Yoga philosophy would explain these changes in behaviour as a return of the body to balance and ease through a mindful attention (Birch, 1995).

Given this, and upon further discussion and review of the student experiences, we agreed to create a parallel analysis of the data using the eightfold path. As previously stated, student learning outcomes regarding the origin and philosophy of Ashtanga yoga are a part of the Yoga 11 curriculum. Again, Ashtanga yoga is described by lyengar (2002) as an eightfold path that includes guidelines for how we treat others (yamas), how we treat ourselves (niyamas), postures (asana), breathwork (pranayama), withdrawal of the senses (pratyahara), concentration (dharana), meditation (dhyana), and enlightenment (samadhi). By interpreting the student narratives through the eightfold path, we believe we provide a deeper understanding of Ashtanga yoga and the benefits of Yoga 11. As qualitative researchers, we believe in the importance of a plurality of interpretations of data, where warranted. It is in this particular sense that researcher bias is not only revealed, but also embraced as a means of generating insight derived from a unique combination of both participant and researcher knowledge and contributions (Moules, McCaffrey, Field, \& Laing, 2015, p. 124). Furthermore, as Moules et al., (2015) offer,

Articulation should not flatten something out, but infuse it with vitality, energy, image, and imagination, in such a way that the articulation itself disappears, and the topic shows itself, perhaps even allowing it to be read in a more generous way than it reads itself. (p. 131)

We offer the following parallel interpretation of the students' experiences in the spirit of providing a generous and reasonable reading of it. This further interpretation is a way of helping the topic be read as more than just the codification and thematization of data. We believe our interpretation is "wellgrounded, justified, and articulated but not presented as incontrovertible" (p. 135). It is certainly not a final answer or interpretation of the students' experiences.

\section{Yamas and Niyamas}

Yoga 11 students are introduced to the philosophical foundation of yoga, which is related to the importance of compassion and kindness to others (yamas) and kindness to self (niyamas). This study of the yamas and niyamas connects to the physical yoga practice, and one student noted how her behaviour changed in relation to herself and others: 
Yoga has just helped me to be friendlier, and to, um, understand other people's perspectives.... It's really just helped me be nicer. I'm a cashier so, um, I've been more friendly to my customers and, um, yeah, and I've been trying to be friendlier to the environment. (Cecelia, transcript excerpt, October 2014)

Cecelia also noted why it was important to be a compassionate human being:

It [yoga] just made you realize that, um, everybody has their own little problems and issues and to be kind to each other. (Cecelia, transcript excerpt, October 2014)

Students were able to make other connections to parts of their lives that would not necessarily be observable to the teacher in the yoga class. From their stories, it appeared that these student behaviours changed because of their present-minded attention to their behaviours, and this was facilitated through the mindful curriculum they experienced in Yoga 11.

\section{Asanas}

Christina was able to build her self-confidence through the experience of the physical postures of yoga, known as asanas. For youth who often struggle with issues of low self-esteem, this story of coming to know and trust her yoga practice was particularly poignant. Christina shared:

I was looking at people doing [the posture of] frog to crow, and I was like, "I don't think I'Il ever be able to do that," and you know I kept thinking, "I have the focus, you know, and I know how to do it because I listened in class. I seen the teacher do it, she showed us multiple times, I seen other people doing it, I know how to do it." So I just decided to try it at home, and eventually I was actually able to do it, not hold it quite yet, but I was able to do it. That was what the best part was though. (Christina, transcript excerpt, October 2014)

All of the students noted, in some variation, that they observed focused and attentive students during the physical practice in asana classes. Christina explained further:

Everyone was actually trying things, even if they knew they couldn't actually do something. Everyone was willing to try and work on it until they could, and I think that's what fired everybody else up. Oh, well, they're trying, I'm going to try it too type thing. (Christina, transcript excerpt, October 2014)

Christina seemed to identify the power of the peer group to modify behavior. She was able to, in her own words, identify that her classmates were focusing on improving their physical postures in yoga class.

\section{Pranayama}

The Yoga 11 students learn techniques to control the rhythm of their breath. This practice is called pranayama and learning to slow down the breath can bring a sense of calmness to the practitioner. Every student reported that they experienced less stress in their lives as a result of their yoga practice. It appears that the students were using asana and pranayama as effective stress coping mechanisms. Sally reported she felt "stress-free" and "I wasn't cranky." She was asked to explain what it meant if she was feeling "stressed-out," offering the following: 
Um, sometimes if I'm really stressed I get a knot in my stomach but just in general I would like, shorter breath.... I'd have my mind on something else, like, it's always off going somewhere else. (Sally, transcript excerpt, October 2014)

Christina shared how her focus on breathing benefited her while she was writing a final exam:

'Cause I know I did that at exams last year. I was freaking out 'cause I know that one of them I didn't study so much for.... I'm freaking out, and you know I just knew my brain started to shut down and I was just like, "I'm not going to get this done, and then I was like, alright, breath work." And I was breathing. And, you know, everything started to clear up and I was like able to pull the answers out of my brain now that I couldn't have before, because I was freaking out so bad. (Christina, transcript excerpt, October 2014)

The students were able to use their knowledge of the yoga practice in many situations and integrated this knowledge into their day-to-day functioning.

\section{Pratyahara and Dharana}

As the study of yoga philosophy progresses, the concepts become more subtle. Moving away from the observable outside body and the asana and pranayama practices, students are introduced to strategies that can activate their senses (pratyahara) such as sight, listening, taste, or touch. Students are asked to focus their attention on one sense, and to practise their concentration (dharana) while doing so. We suggest that Yoga 11, as a mindfulness curriculum, can be facilitated such that a student like Tommy can see himself as capable of concentration and relaxation, such that he may also positively learn from that state of directed attention:

Well, me, myself, I'm a pretty outgoing person. I'm kind of a jokester in a way, and for yoga, I was surprised I could still be my open jokester self but at the same time you really take the time to relax and focus on what you are doing. And that is something you really need to work on, especially me, because you really need to calm down and settle. And yoga, just, it comes so naturally, and like when you actually just focus on what you are doing, it's hard not to be relaxed. It's just, it does wonders really. (Tommy, transcript excerpt, October 2014)

Cecelia also felt more focus as a result of her mindfulness practice:

I noticed that I was a lot more focused, um, I'm like, kind of a daydreamer so I was focusing on, like, my breath and like my next move and everything was, it just made me really focus on what I was doing in the present. (Cecelia, transcript excerpt, October 2014)

All students interviewed expressed that the yoga practice helped them to focus their attention and limit distractions. Consider Tommy's comments:

Well, you always feel great after a yoga practice. I always said like I'd be physically and mentally relaxed at home, everything is connected in a way again. (Tommy, transcript excerpt, October 2014)

From the students' stories of experiences, it appears they were using their yoga practice to mediate stressful situations. 


\section{Dhyana and Samadhi}

The traditional practice of Ashtanga yoga was considered a lifelong practice that could eventually enable the practitioner to experience meditation (dhyana) and enlightenment (samadhi) or bliss (Birch, 1995). The introductory high school Yoga 11 course does not expect students to achieve these yogic states of consciousness. However, the students shared stories about how they were able to experience blissful and happy moments in relation to their yoga practices:

I love nature, like just looking out the window right now and seeing all the different colours. Yoga really made me realize to just sit down, breathe, and just look, enjoy, see, instead of just sitting. I could just go sit outside and think about the million things that I'm stressing about, or I can just enjoy the moment and look at the beauty that's right in front of me. It took me a long time to realize I have to enjoy simple moments like that but yoga just opened your eyes to it. (Tommy, transcript except, October 2014)

Tommy was able to equate his personal happiness to his experiences in Yoga 11:

For you to be truly happy you need to learn to balance everything, from family, to exercise, to school. That's a hard task, and yoga really takes a big role in that. (Tommy, transcript excerpt, October 2014)

Students showed hints of deeper understanding. They were using the physical practice as a metaphor for being strong and balanced on and off the yoga mat. Christina explained, "maybe your asanas are modified a little bit, but you know, modifications only last so long." She came to know that her physical practice would get stronger with patience and perseverance.

When asked if she noticed a change in her understanding of yoga after completing Yoga 11, Christina explained in the following story how she used her experience of yoga to become more mindful of her self-confidence:

I think that it [yoga] has definitely changed my understanding on everything, on yoga... before I took yoga, I say that a lot, it's like I was the person before I started yoga and the person after I did yoga. I think that the person that I was when I took yoga, it was almost like my brain kind of opened, and my heart kind of opened into things that you know I normally wouldn't have tried before because: (a) I was either too scared, or thought I'd get made fun of. But it's like I understand everything just completely different. I'm able to do a lot more than I thought. (Christina, transcript except, October 2014)

The students explained how they were able to use their yoga practice in all kinds of situations. They integrated knowledge of mindfulness practices into the day-to-day functioning of their experiences. They facilitated their own ability to self-regulate in stressful situations. These students experienced specific mental health benefits through their yoga practice. 


\section{Conclusion and Future Considerations}

The Yoga 11 students experienced mental health benefits as a result of their mindfulness practices and learning. The student responses support the research on mindfulness in education and the mental health benefits of yoga. Additionally, and importantly, their responses reinforce the importance of their understanding of the connection between yoga as a mindfulness practice and mental health. At a time when mindfulness in education is at once popular and contested (Gunther Brown \& Santorelli, 2016), this study has helped reinforce the benefits of mindfulness in education, particularly when it is taken up as curriculum. Yoga 11 is, in and of itself, a course on mindfulness, we offer. As such, students leave the course understanding that the study and practice of mindfulness, via the curriculum of Ashtanga yoga, benefits their overall health, particularly their mental health. Given this, we wonder if yoga courses like Yoga 11 could contribute as effective proactive upstream curricula as intervention possibilities for student distress, mental health problems, and illnesses. Not only does Yoga 11 teach students stress-reduction and self-regulation practices; but the philosophy within the curriculum also offers a helpful pathway for adapting — both socially and individually — to the necessary stressors of human life. Kindness to self and others can go a long way to helping us through difficult times, we believe.

At the least, educators and educational program stakeholders could use this research to make informed decisions on how to effectively promote mental health into the school setting. This investigation shows evidence that students perceive yoga as one strategy that may improve mental health. This study has potential to encourage other researchers to inquire upon the benefits of yoga for youth. Perhaps it will be used to promote the use of yoga in schools, as it clearly explains how students are experiencing benefits from the practice. Although this study focused specifically upon the Yoga 11 program, yoga can be easily implemented into all grade levels. A future consideration may be to develop and implement yoga curriculum that would be appropriate for younger students, as well as an advanced continuation of the Yoga 11 high school program, possibly called Yoga 12. School boards may want to consider funding professional development to train more yoga teachers.

\section{References}

Birch, B. B. (1995). Power yoga: The total strength and flexibility workout. New York: Fireside.

Chugh-Gupta, N., Baldassarre, F. G., \& Vrkljan, B. H. (2013). A systematic review of yoga for state anxiety: Considerations for occupational therapy. Canadian Journal of Occupational Therapy, 80(3), 150-170. doi:10.1177/0008417413500930

Clandinin, D. J. (2006). Narrative inquiry: A methodology for studying lived experience. Research Studies in Music Education, 27(1), 44-54. doi:10.1177/1321103X060270010301

Clandinin, D. J., Pushor, D., \& Murray Orr, A. (2007). Navigating sites for narrative inquiry. Journal of Teacher Education, 58(1), 21-35. doi:10.1177/0022487106296218

Conboy, L., Noggle J., Frey J., Kudesia, R., \& Khalsa, S. (2013). Qualitative evaluation of a high school yoga program: Feasibility and perceived benefits. Explore, 9(3), 171-180. 
Greenberg, M. T., \& Harris, A. R. (2012). Nurturing mindfulness in children and youth: Current state of research. Child Development Perspectives, 6(2), 161-166.

Gunther Brown, C., \& Santorelli, S. (2016). Does mindfulness belong in public schools? Tricycle, 25(3). Retrieved from http://www.tricycle.com/feature/does-mindfulness-belong-public-schools

Hainsworth, K., Salamon, K., Khan, K., Mascarenhas, B., Davis, W., \& Weisman, S. (2014). A pilot study of yoga for chronic headaches in youth: Promise amidst challenges. Pain Management Nursing, 15(2), 490-498.

lyengar, B. K. S. (2002). Light on the yoga sutras of Patanjali. London, England: Thorsons.

Meiklejohn, J., Phillips, C., Freedman, M. L., Griffin, M. L., Biegel, G., Roach, A., et al. (2012). Integrating mindfulness training into K-12 education: Fostering the resilience of teachers and students. Mindfulness, 3(4), 291-307.

Merriam, S. B. (Ed.). (2009). Qualitative research: A guide to design and implementation. San Francisco: Jossey-Bass.

Moules, N. J., McCaffrey, G., Field, J. C., \& Laing, C. M. (2015). Conducting hermeneutic research: From philosophy to practice. New York: Peter Lang.

Noggle, J., Steiner, N., Minami, T., \& Khalsa, S. (2012). Benefits of yoga for psychosocial well-being in a US high school curriculum: A preliminary randomized controlled trial. Journal of Developmental and Behavioral Pediatrics, 33(3), 193-201.

Nova Scotia Department of Education. (2010). Yoga 11 outcomes. Halifax, Canada: Author.

Patton, MQ. (2001). Qualitative research and evaluation methods (2nd edition). Thousand Oaks, CA: Sage Publications.

Physical and Health Education Canada. (2014a). Mental health education in Canada: An analysis of teacher education and provincial/territorial curricula. Ottawa, Canada: Author.

Physical and Health Education Canada. (2014b). The responsibility to promote resiliency: Public perspectives on mental health education and the Canadian school system. Ottawa, Canada: Author.

Robinson, D. B., \& Berezowski, K. (2016). The Yoga 11 experience: A case study of an "alternative" physical education course. Revue phénEPS/PHEnex Journal, 8(1), 1-21.

Salmon, P., Lush, E., Jablonski, M., \& Sephton, S. E. (2009). Yoga and mindfulness: Clinical aspects of an ancient mind/body practice. Cognitive and Behavioral Practice, 16(1), 59-72.

Schonert-Reichl, K., \& Stewart Lawlor, M. (2010). The effects of a mindfulness-based education program on pre- and early adolescents' well-being and social and emotional competence. Mindfulness, 1(3), 137-151.

Sharma, M., \& Haider, T. (2013). Yoga as a complementary therapy for patients suffering from anxiety: A systematic review. Journal of Evidence-Based Complementary \& Alternative Medicine, 18(1), 15-22.

Shelov, D. V., Suchday, S., \& Friedberg, J. P. (2009). A pilot study measuring the impact of yoga on the trait of mindfulness. Behavioural and Cognitive Psychotherapy, 37(5), 595-598.

White, L. S. (2012). Reducing stress in school-age girls through mindful yoga. Journal of Pediatric Health Care, 26(1), 45-56. doi:10.1016/j.pedhc.2011.01.002 


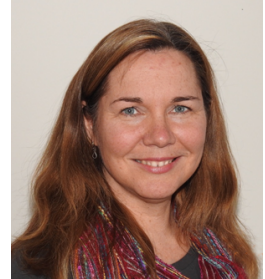

Karen A. Berezowski, Med, is a public school teacher at Northumberland Regional High School. She teaches Yoga 11, and piloted the high school yoga program in 2007. She is also a part-time instructor at St. Francis Xavier University, and teaches a graduate course in mindfulness for educators. She also presents professional development workshops for teachers in the Chignecto-Central Regional School Board. Ms. Berezowski's research focuses on students' experiences of the mental and physical health benefits of Yoga 11.

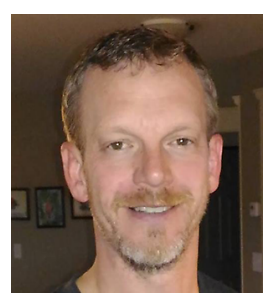

Christopher M. Gilham, PhD, is an Assistant Professor at St. Francis Xavier University. He teaches undergraduate courses in inclusion, mental health education and sociology of education. He also teaches graduate courses in current research in mental health education, mindfulness in education, and critical research literacy. Dr. Gilham's research focusses on mental health literacy, inclusive education, and mindfulness in education.

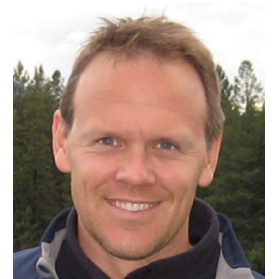

Daniel B. Robinson, PhD, is an Associate Professor and Chair of Teacher Education at St. Francis Xavier University. He teaches undergraduate courses in elementary and secondary physical education curriculum and instruction. He also teaches graduate courses in current research in curriculum and instruction, administration of inclusive schools, curriculum theory, and school and teaching effectiveness. Dr. Robinson's research focuses on culturally responsive physical education, gender and racialized minorities, service learning, and in-school health promotion programming. 